\title{
Consolidação de atos normativos: a especificidade da técnica legislativa e a consolidação do Sistema Único de Saúde
}

Consolidation of enacted statutes: the specificity of the legislative technique and the consolidation of the Unified Health System

Consolidación de actos normativos: la especificidad de la técnica legislativa y la consolidación del Sistema Único de Salud

Marcio lorio Aranha ${ }^{1}$ João Alberto de Oliveira Lima²

\section{Resumo}

Objetivo: o objetivo central do artigo é o de identificar a função e o regime jurídico específico da consolidação de atos normativos, enquanto instituição de direito público, tendo por base a experiência consolidadora modelar do Sistema Único de Saúde (SUS). Metodologia: a interpretação dos diplomas normativos pertinentes à elaboração, redação, alteração e consolidação de atos normativos obedeceu à hermenêutica prescritiva ou metodológica, aplicando-se os cânones da autonomia hermenêutica do objeto, expressa na máxima sensus non est inferendus sed efferendus; da coerência de sentido ou princípio da integralidade; da atualidade da compreensão; e da correspondência hermenêutica de sentido ou harmonização, tomando-se por tipos ideais os constructos da garantia institucional, do neoinstitucionalismo jurídico e das normas de ocorrência singular, e por pressuposto a objetividade da interpretação de E. D. Hirsch. Resultados: a função da consolidação é tanto de momento de ajuste de técnica legislativa, quanto, principalmente, de garantia institucional do princípio da segurança jurídica, revelada por suas características de norma singular de atualização contínua e permanente de sistemas normativos e de reestruturação orgânica neoinstitucional de diplomas normativos esparsos. O diferencial funcional da categoria jurídica da consolidação, por sua vez, impõe um regime jurídico distinto daquele aplicado às categorias normativas ordinárias, configurando-se em etapa processual legislativa ou normativa alheia à inovação e imune a exigências formais de numeração sequencial e vigência diferida. Conclusão: a interpretação das normas sobre elaboração, redação, alteração e consolidação das normas federais vigentes no Brasil, bem como o uso do parâmetro teórico do neoinstitucionalismo jurídico, evidenciaram a distinção funcional e de regime jurídico da consolidação frente às categorias normativas ordinárias presentes no ordenamento jurídico brasileiro.

\section{Palavras-chave}

Portarias. Sistema Único de Saúde. Consolidação de normas.

\footnotetext{
Abstract

Objetive: to identify the legal regime and legal functions of normative consolidations as public law institutions, taking into consideration the recent approval of the Brazilian Unified Health

${ }^{1}$ Pós-Doutor, University of Southern California, Los Angeles, Estados Unidos da América; Doutor em Políticas Públicas Comparadas, Universidade de Brasília, Brasília, DF, Brasil; Professor Associado III, Faculdade de Direito da Universidade de Brasília, Brasília, DF, Brasil. https://orcid.org/0000-0001-9436-0987. E-mail: iorio@ccom.unb.br

2 Doutor em Direito, Universidade de Brasília, Brasília, DF, Brasil; Doutor em Ciência da Informação, Universidade de Brasília, Brasília, DF, Brasil; Analista de Informática Legislativa, Senado Federal, Brasília, DF, Brasil. https://orcid.org/00000001-9830-5272. E-mail: joaolima@senado.leg.br
} 
System consolidation. Methodology: based on prescriptive or methodological hermeneutics, this article applies Betti's canons of (i) the hermeneutical autonomy of the object, expressed in the maxim sensus non est inferendus sed efferendus, (ii) the coherence of meaning or principle of totality, (iii) the actuality of understanding, and (iv) the hermeneutical correspondence of meaning or harmonization. It also adopts as ideal-types, the legal constructs of institutional guarantees, neoinstitutionalism and nonsequential statutes, based on the assumption of Hirsch's objectivity of interpretation. Results: consolidation, as a legal institution, plays two main roles: (i) It fosters a juridical-technical harmonization of the norm in itself and in relation with the other norms on related topics; (ii) It presents itself as an institutional guarantee of the principle of legal certainty, due to its features of continuous renewal of the normative content and neoinstitutional reengineering of sparsely positioned norms in an organic set of interrelated legal content. The legal institution of the consolidation is characterized by a specific legal regime: (i) Firstly, it figures as a normative procedural step that avoid innovation; (ii) Secondly, it is exempted of the sequential numbering of the norms and several rules pertaining entry into force. Conclusion: the interpretation of federal acts in Brazil on legal drafting, writing, changing and consolidation, and the use of neoinstitutional underpinnings brings to light the specific role played by the consolidation and the unique functional and legal regime when compared to the ordinary normative categories in the Brazilian Law.

\section{Keywords}

Ordinances. Unified Health System. Normative Consolidation.

\section{Resumen}

Objetivo: identificar el régimen y las funciones legales de las consolidaciones normativas como instituciones de derecho público, tomando en consideración la reciente aprobación de la consolidación del Sistema Único de Salud Brasileño. Metodología: basado en la hermenéutica prescriptiva o metodológica, este artículo aplica los cánones de Betti de (i) la autonomía hermenéutica del objeto, expresada en la máxima sensus non est inferendus sed efferendus, (ii) la coherencia de significado o principio de la totalidad, (iii) ) la actualidad del entendimiento, y (iv) la correspondencia hermenéutica de significado o armonización. También adopta como tipos ideales, las construcciones legales de las garantías institucionales, el neoinstitucionalismo y las normas de ocurrencia singular, basado en el supuesto de la objetividad de interpretación de Hirsch. Resultados: la consolidación, como institución jurídica, juega dos roles principales: (i) fomenta una armonización jurídico-técnica de la norma en sí misma y en relación con las demás normas en temas relacionados; (ii) se presenta como garantía institucional del principio de seguridad jurídica, por sus características de renovación continua del contenido normativo y reingeniería neoinstitucional de normas escasamente posicionadas en un conjunto orgánico de contenido jurídico interrelacionado. La institución jurídica de la consolidación se caracteriza por un régimen jurídico específico: (i) en primer lugar, figura como un paso procesal normativo no inovador; y (ii) en segundo lugar, se exime de la numeración secuencial de las normas y de reglas básicas a la entrada en vigor de la norma. Conclusión: la interpretación de las leyes federales en Brasil sobre redacción, cambio y consolidación legal, y el uso de fundamentos neoinstitucionales, pone de manifiesto el papel específico que juega la consolidación y su régimen funcional y legal único en comparación con las categorías normativas ordinarias en la ley brasileña.

\section{Palabras clave}

Ordenanzas. Sistema Único de Salud. Consolidación Normativa. 


\section{Introdução}

A consolidação de normas, enquanto instrumento normativo dotado de características específicas, é um ser ainda pouco conhecido na prática institucional brasileira. Enquanto outros países, notadamente da tradição anglo-americana, há muito consolidam suas normas em temas conexos, evitando-se, assim, o acúmulo de normas esparsas (1, p. 237-254), no Brasil, o esforço consolidador tem sido implementado, sem sucesso, desde a publicação da Lei Complementar $n^{\circ}$ 95, de 1998, com renovada esperança de revisão e consolidação ampla dos diplomas normativos federais a partir do chamado Decreto do Revisaço (2).

Não foi por ausência de vontade política e esforço burocrático que a União deixou de alcançar o desiderato da organização das normas em consolidações. Nada menos do que a própria Constituição, uma lei complementar, vários decretos e inúmeras portarias ministeriais caminharam nesse sentido entre a segunda metade da década de 1990 e toda a década de 2000.

Ao elencar os instrumentos produzidos pelo processo legislativo - a elaboração de emendas à Constituição, leis complementares, leis ordinárias, leis delegadas, medidas provisórias, decretos legislativos e resoluções - o art. 59 da Constituição Federal de 1988 culmina com a previsão, no seu parágrafo único, de reserva legal qualificada por lei complementar para regulamentação da elaboração, redação, alteração e consolidação das leis. Com isso, a Constituição identificou a consolidação como um dos quatro pilares da vida institucional das leis.

A Lei Complementar $n^{\circ}$ 95, de 1998, que regulamenta o artigo inaugural do processo legislativo na Constituição de 1988, dispondo sobre a elaboração, redação, alteração e consolidação das leis, dedica quase metade de seus dispositivos ao tema, no Capítulo III (Da Consolidação das Leis e Outros Atos Normativos), em que determina que as leis federais serão reunidas em codificações e consolidações, integradas por volumes contendo matérias conexas ou afins, constituindo em seu todo a Consolidação da Legislação Federal. Tamanha a importância da consolidação, que a LC n 95/98 previa, inicialmente, o prazo de 180 dias para a Presidência da República e os Ministérios realizarem o exame, triagem, seleção e consolidação das normas primárias federais; de 90 dias para as entidades da administração indireta promoverem o mesmo quanto aos diplomas legais referentes a sua competência; e o prazo de 180 dias do recebimento dos textos para publicação, pelo Congresso Nacional, da primeira Consolidação das Leis Federais Brasileiras. Se esses prazos de lei complementar tivessem sido cumpridos, a Consolidação da Legislação Federal já teria completado vinte e um anos de idade. 
Os autores da LC n 95/98, entretanto, desprezaram a real complexidade e dimensão da empreitada consolidadora. Mesmo com o apoio da área de informática do Senado Federal, que desenvolveu o sistema de consolidação SISCON em poucos meses a partir de demanda da Casa Civil, o esforço empregado pelos ministérios para realizar a consolidação temática não foi suficiente para realizar o que se almejava. Apenas 10 projetos de revogação foram encaminhados ao Congresso Nacional (1, p. 289) e, "apesar do valor da iniciativa, do esforço empregado e dos projetos de revogação ou de consolidação formulados, a 'consolidação da legislação brasileira' não aconteceu e o parlamento nacional nada aprovou" (1, p. 292). O reconhecimento de que os prazos seriam inexequíveis forçou o Congresso Nacional a revogar ou alterar os dispositivos pertinentes, extirpando-os da LC $n^{\circ}$ 95/98, via LC no 107/2001. A partir daí, permaneceu vigente a determinação da LC n 95/98 de consolidação das leis e atos normativos federais sem, contudo, existir um prazo legal para seu cumprimento.

A quantidade faraônica de normas de nível federal, estadual e municipal no Brasil também explica o desalento e a frustração de iniciativas de consolidação de leis e atos normativos infralegais nas últimas décadas. Desde a promulgação da Constituição de 1988, estima-se terem sido editadas, no Brasil, em torno de 774 normas por dia útil, alcançandose um total de mais de 5,9 milhões de normas publicadas no período de 1988 a 2018 (2). Some-se a isso o fato de que o esforço de consolidação de normas depende de uma abordagem interdisciplinar de direito, ciência da informação, filosofia da linguagem e lógica (3), e os ingredientes para o insucesso da grande maioria de iniciativas de consolidação, no Brasil, estarão completos.

A despeito da centralidade da consolidação para o processo legislativo e, por decorrência, para o processo normativo, em geral, ela permanece desconhecida para o grande público, com raras repercussões concretas - a Consolidação do SUS é uma notória exceção. Estudos sobre o regime jurídico da consolidação também são dispersos, como demonstra Rizek Júnior (1, p. 10) em seu amplo diagnóstico sobre a consolidação no direito comparado. No Brasil, a conjugação entre pesquisa acadêmica e implementação prática de modelagem consolidadora, somente tem por exemplo o esforço da Consolidação do SUS, desenvolvendo e aplicando em um caso concreto uma heurística baseada em abordagem interdisciplinar (3).

Este artigo adentra um tema de estudo escasso na literatura nacional e tem por foco central o de identificar a função e o regime jurídico específico da instituição de direito público da consolidação de atos normativos, tendo por base empírica a experiência consolidadora 
modelar do Sistema Único de Saúde (SUS). Para tanto, promove-se a interpretação dos diplomas normativos pertinentes à elaboração, redação, alteração e consolidação de atos normativos, sob o pressuposto de objetividade interpretativa da tradição hermenêutica prescritiva ou metodológica desenvolvida por Dilthey e Betti, em oposição ao relativismo interpretativo, aplicando-se os cânones de autonomia hermenêutica do objeto, de coerência de sentido, de atualidade da compreensão e de correspondência hermenêutica dos significados (4, p. 188). A hermenêutica prescritiva reconhece a necessária correspondência entre formas significativas inscritas em produções culturais, das quais as normas são espécie, e tipos-ideias atuais atribuidores de significado na mediação entre as subjetividades dos criadores das normas e dos intérpretes. Por isso, o método hermenêutico depende do esclarecimento desses tipos-ideais. Aqui, adotam-se três tipos-ideais utilizados para a reconstrução das mensagens originais inscritas nas formas significativas dos diplomas normativos disciplinadores da consolidação: são eles os constructos da garantia institucional, do neoinstitucionalismo jurídico e das normas de ocorrência singular.

Ainda na linha de esclarecimento dos pressupostos metodológicos, parte-se do pressuposto da possibilidade do conhecimento objetivo mediante elenco de evidências interpretativas, na linha do objetivismo hermenêutico defendido por Hirsch (5, p. 180-198) ao criticar os teóricos defensores do relativismo interpretativo, em especial os principais representantes da hermenêutica filosófica - Heidegger, Gadamer e Ricoeur -, que deixam de promover a separação estrita entre descrição e avaliação do texto e, com isso, confundem os momentos interpretativos do sentido original objetivo e dos diversos significados atribuídos pelos leitores. Na esteira da distinção crucial entre sentido e significado (5, p. 810; 38-57), este artigo endereça o sentido objetivo do ordenamento jurídico federal brasileiro sobre elaboração, redação, alteração e consolidação de diplomas normativos, sem perder de vista que a interpretação jurídica é um complexo de atividades hermenêuticas (6) e que o presente esforço de identificação da intencionalidade do legislador configura um passo essencial para o mosaico da concepção multifacetada de hermenêutica.

O artigo está dividido em duas partes. A primeira delas destina-se à interpretação funcional da consolidação, mediante identificação das finalidades distintivas da categoria consolidadora frente às demais categorias de normas ordinárias. A segunda parte, por sua vez, dedica-se à identificação da especificidade do regime jurídico da consolidação, traçando consequências jurídicas de técnica legislativa daí decorrentes. 


\section{O papel da consolidação}

A evidência do caos normativo experimentado no Brasil é vasta. Na área de saúde, basta citar o exemplo da Portaria GM/MS n².048, de 3 de setembro de 2009, resultado do esforço considerável de uma Comissão Permanente de Consolidação e Revisão de Atos Normativos do Ministério da Saúde, criada pela Portaria GM/MS n 1.035, de 4 de junho de 2002, com alteração de composição advinda da Portaria GM/MS n 1.208, de 22 de maio de 2007.

A criação dessa comissão respondia à determinação do Decreto $n^{\circ} 4.176$, de 28 de março de 2002, que regulamentava, à época, a LC n 95/98, estabelecendo normas e diretrizes para a elaboração, a redação, a alteração, a consolidação e o encaminhamento ao Presidente da República de projetos de atos normativos de competência dos órgãos do Poder Executivo Federal. A Portaria GM/MS n 815, de 29 de abril de 2008, por sua vez, havia aprovado o Regimento Interno da Comissão Permanente de Consolidação e Revisão de Atos Normativos do Ministério da Saúde, atribuindo-lhe, no art. $2^{\circ}$, IV, a competência para elaborar e revisar, periodicamente, o Regulamento do Sistema Único de Saúde (SUS), a partir da legislação infralegal consolidada, dispondo sobre sua organização e funcionamento. A Portaria $n^{\circ} 2.048 / 2009$ teria sido o primeiro caso de consolidação do SUS sob o codinome de Regulamento do Sistema Único de Saúde não fossem os inúmeros problemas de desestruturação normativa e imprecisão nela existentes, impondo a suspensão de sua eficácia alguns dias após sua publicação. Tratava-se de uma portaria de grandes dimensões - 790 artigos e dezenas de anexos - e grande impacto - 109 portarias com normas gerais e abstratas do SUS revogadas.

A compreensão da dimensão de insegurança jurídica gerada demanda uma descrição mais detalhada do histórico da Portaria $n^{\circ}$ 2.048/2009. Ela foi publicada em 4 de setembro de 2009, entrando em vigor na data de sua publicação, revogando 109 portarias relevantes do SUS. Após dezenove dias em vigor, a Portaria GM/MS n 2.230, de 23 de setembro de 2009, alterou a cláusula de vigência da Portaria $n^{\circ} 2.048 / 2009$, e, sob o fundamento de que as peculiaridades do processo de consolidação de atos normativos exigiriam a instituição de margem temporal para permitir maior conhecimento do texto elaborado e sua atualização, postergou a entrada em vigor da Portaria n² 2.048/2009 para um ano após sua publicação, o que, por si só, já configurava um atentado à lógica consolidadora, pois, ao não inovar no ordenamento jurídico e ter sua vigência postergada, gerava um perigoso hiato normativo, tendo em vista que as normas que ela revogava poderiam ter suas redações alteradas durante a vacatio legis. 
A experiência malsucedida da Portaria 2.048/2009 revela dois aspectos fundamentais de técnica legislativa de consolidações: a) o primeiro deles é de que elas devem ser elaboradas com apoio na ciência da informação e ciência da computação para a garantia da preservação do conteúdo normativo original das normas de origem; para seguir um método de análise e avaliação do conteúdo consolidável dependente de conhecimento jurídico e técnico da matéria tratada e se estruturar segundo teorias que possam organizar o conteúdo normativo em instituições aglutinadoras capazes de fazer frente à evolução normativa futura, e; b) devem entrar em vigor no dia de sua publicação, sob pena de descumprirem o mandamento básico de revogação formal dos diplomas normativos incorporados na consolidação e manutenção, sem modificação do alcance nem interrupção da força normativa, dos dispositivos consolidados.

Os problemas da Portaria $n^{\circ} 2.048 / 2009$, entretanto, somente tinham começado. A vacatio legis tardiamente aplicada pela Portaria $n^{0} 2.230 / 2009$ à Portaria $n^{0} 2.048 / 2009$ acenava com a entrada em vigor do Regulamento do Sistema Único de Saúde diferida para 24 de setembro de 2010. Em 17 de setembro de 2010, todavia, com a publicação da Portaria GM/MS n².792, de 15 de setembro de 2010, ela foi novamente estendida em 180 dias para entrada em vigor em 18 de março de 2011. Em $1^{\circ}$ de março de 2011, a Portaria GM/MS n 319 , de 28 de fevereiro de 2011, novamente prorrogou o prazo de vacatio legis por mais um ano, até 28 de fevereiro de 2012. Por descuido, nova prorrogação somente foi publicada após a efetiva entrada em vigor da Portaria $n^{\circ}$ 2.048/2009. Em 6 de março de 2012, foi publicada a Portaria GM/MS n 373, de 5 de março de 2012, suspendendo a vigência da Portaria $n^{\circ} 2.048 / 2009$ por mais um ano até 5 de março de 2013. Com isso, a Portaria $n^{\circ}$ 2.048/2009 acumulava dois breves períodos de vigência, entre 4 e 23 de setembro de 2009 e entre $1^{\circ}$ e 5 de março de 2012, com a agravante de que se tratava de uma portaria que revogada 110 portarias de funcionamento de um dos maiores sistemas públicos de saúde do mundo. Como bom filme de terror, os dois breves períodos de vigência e os inúmeros problemas de direito intertemporal gerados empalidecem frente ao que estava por vir. Em 6 de março de 2013, ausente nova portaria de prorrogação da vacatio legis, a Portaria $\mathrm{n}^{\circ}$ $2.048 / 2009$ voltou a entrar em vigor, tendo sido relegada ao esquecimento, pois de 2013 a 2017, permaneceu em vigor, mas as portarias por ela expressamente revogadas foram aplicadas pelo Ministério da Saúde e até mesmo por decisões judiciais como se a Portaria $\mathrm{n}^{\circ} 2.048 / 2009$ nunca houvesse existido. Somente com a publicação das Portarias de Consolidação GM/MS, em 3 de outubro de 2017, a Portaria $n^{\circ}$ 2.048/2009 foi finalmente revogada, tendo o texto histórico das portarias que ela havia revogado, com as inúmeras 
alterações e atualizações promovidas por outras centenas de portarias sido incorporado na atual Consolidação do SUS.

A insegurança jurídica gerada pela publicação, entrada em vigor, prorrogação de entrada em vigor, nova entrada em vigor, nova prorrogação de entrada em vigor, e nova entrada em vigor por mais quatro anos, sem que a maioria dos atores do SUS sequer tomasse conhecimento de sua existência, persistindo o respeito, de fato, às normas revogadas pela Portaria $n^{\circ} 2.048 / 2009$ foi incalculável. Incalculável mormente por força do caos normativo, que permitiu que essa ruptura normativa sem precedentes passasse praticamente despercebida por juízes, promotores, procuradores, defensores e advogados públicos e privados Brasil afora em um dos temas mais relevantes da judicialização no País (7). Era tão surpreendente a situação jurídica da Portaria n 2.048/2009, que a bibliotecária jurídica do projeto de pesquisa que deu origem às seis portarias de consolidação resolvendo enfim o imbróglio normativo do SUS - apelidava o árduo processo de avaliação dos dispositivos da Portaria $n^{\circ} 2.048 / 2009$ de uma verdadeira exumação. O problema de aplicação, de fato, de normas revogadas no âmbito do SUS somente foi resolvido com a publicação das seis portarias de consolidação GM/MS do SUS, em 3 de outubro de 2017. Pode-se dizer que o caos de segurança jurídica somente foi evitado, à época, pelo caos normativo em vigor, que reservava uma sensação de pânico àqueles poucos que tinham conhecimento do problema e que, por respeito ao SUS, não o expunham.

Esse exemplo dramático de tentativa frustrada de consolidação das normas do SUS evidencia o papel proeminente da consolidação em, ao organizar as normas até então pulverizadas em diplomas normativos esparsos, sedimentar uma nova estruturação normativa capaz de ordenar o passado e, sobretudo, servir de garantia institucional da segurança jurídica, mediante enunciado unificado e transparente do arsenal normativo em vigor. Além da capacidade de ordenar o passado, a lógica empregada na sistematização interna e externa deve contemplar uma estrutura capaz de acomodar as normas gerais e permanentes que venham a ser publicadas.

Entende-se por garantia institucional toda construção institucional voltada a salvaguardar o núcleo essencial de um princípio fundamental, preservando o conteúdo jurídico em meio a enunciados jurídicos sensíveis à transformação (8, p. 168). A consolidação, como momento processual de preservação do sistema de normas sobre matérias conexas ou afins em meio às transformações contínuas oriundas de novas normas ocupa uma posição proeminente no esquema institucional de garantia da segurança jurídica, ela mesma um princípio que rivaliza com o da legalidade (9). 
Não é novidade o entendimento de que esforços codificadores das leis suportariam a segurança jurídica - ela mesma uma garantia institucional (10, p. 152) -, mesmo por quem via no movimento codificador alemão do século XVIII a capitulação dos principados à ação corruptora francesa (11, p. 38). É bem verdade que Savigny se posicionava contra o "ardor cego pela organização" (11, p. 39) característico da última metade do século XVIII, mas o fazia opondo-se ao desprezo pelo passado e à petrificação do direito em códigos. O diferencial entre a consolidação de normas e a codificação reside precisamente no fato de que a consolidação, ao contrário dos códigos, é o próprio passado normativo organizado e disposto à atualização.

A funcionalidade da consolidação como garantia institucional é de segundo nível, pois depende da adequada implementação de sua função primordial: a de organização do conteúdo normativo. Essa organização poderia ser inaugural, se determinado âmbito de competência estatal pudesse, desde o nascedouro, conformar-se via consolidação. $\mathrm{Na}$ prática institucional brasileira, todavia, as consolidações surgem em meio a disposições normativas esparsas e, para além de cumprirem a função de organização do conteúdo normativo, o fazem via reestruturação normativa de diplomas esparsos vigentes em determinado momento, como foi o caso da Consolidação do SUS, que reestruturou em poucas portarias de consolidação e em uma resolução de consolidação centenas de diplomas normativas efetivamente reorganizados em dois momentos do esforço consolidador: 2017 e 2020-2021. Independentemente da peculiaridade de tomar a consolidação como forma inaugural ou tardia de organização normativa, a característica funcional própria à consolidação encontra-se na finalidade de organização normativa.

Essa organização é, por definição, parametrizada. Os parâmetros não advêm, entretanto, das próprias normas de elaboração, redação, alteração e consolidação normativa, que se preocupam somente com o processo de consolidação. Essa ausência de parâmetros de organização normativa, para além da estrutura de agrupadores normativos, evidencia a importância de uma ciência da consolidação capaz de informar os esforços consolidadores com teorias adequadas a sedimentarem estruturas orgânicas de normas aptas a lidarem com a dinâmica de evolução de determinada competência consolidada.

Assim, pode-se lançar mão de uma miríade de fundamentos garimpados, e.g., na Teoria Geral da Terminologia (12), na Teoria Geral da Ordem (13), na Teoria Analítica dos Conceitos (14), na Teoria da Classificação $(15,16)$, em modelos delas derivados, como o Modelo Genérico de Relacionamentos (17), bem como em uma proposta atualizada de construção interdisciplinar da consolidação em que se propõe um método próprio, tendo 
como empiria a Consolidação do SUS, via união entre o neoinstitucionalismo e a Teoria dos Conceitos Jurídicos Fundamentais (3).

Segundo Neil MacCormick (18, p. 51-53), o conceito de instituição jurídica possui um duplo poder sistematizador, permitindo lidar tanto com a complexidade, como também com a extensão das normas jurídicas. Ao identificarmos e hierarquizarmos as instituições declaradas por meio de normas jurídicas, cria-se um novo nível de abstração, no qual passase a consolidar instituições jurídicas, e não mais uma miríade de enunciados normativos.

Foi propriamente essa a sistemática empregada na Portaria de Consolidação GM/MS $\mathrm{n}^{\circ} 2$, que consolidou as políticas públicas relativas ao SUS. Antes dessa norma, não se sabia, de forma objetiva, quantas políticas públicas de saúde haviam sido instituídas desde a criação do SUS. Ressalte-se ainda que, no ano seguinte à publicação dessa consolidação, o Ministro da Saúde instituiu a Política Nacional de Atenção Integral à Saúde do Povo Cigano/Romani, fazendo apenas o acréscimo de um inciso ao art. $5^{\circ}$, que trata das políticas de equidade, e de um anexo com o texto da nova política, que foi devidamente encaixada na arquitetura da consolidação.

A relação entre a visão neoinstitucional e os conceitos jurídicos fundamentais de Wesley Newcomb Hohfeld (1879-1918) se dá pela realização de atos institucionais por agentes portadores das disposições previstas nos conceitos jurídicos fundamentais de Hohfeld (19, p. 8-9). É por meio da aplicação de uma norma constitutiva, como o exercício de uma competência, que são definidas as posições jurídicas em relações intersubjetivas, sejam as relativas às normas de conduta ou mesmo em relação a outras normas constitutivas, como no caso de delegação de competência para a realização de uma política pública. Por esse motivo, em uma consolidação, as normas constitutivas devem preceder as de conduta na sistematização interna dos dispositivos.

As funções de garantia institucional da segurança jurídica e de ambiente de reestruturação orgânica neoinstitucional de temas conexos e afins de diplomas normativos esparsos não esgotam o propósito de uma consolidação. Ela também serve como momento de ajuste da técnica legislativa. Problemas de técnica legislativa abundam no ordenamento jurídico pátrio. No SUS, Delduque e Passos (20) identificaram uma profusão de problemas de redação normativa nas portarias normativas do Gabinete do Ministro da Saúde referentes ao SUS entre 1998 e 2017, evidenciando problemas de ausência de avaliação de impacto legislativo; de desconhecimento das normas em vigor; de publicações em duplicidade; de ausência de análise de impactos orçamentários e financeiros; de conflitos de normas; de deficiência de ementas; de uso indevido de siglas e acrônimos; de equívocos de numeração 
de dispositivos; de erros no desdobramento de artigos; de presença de revogações indiretas ou tácitas; de equívocos em remissões entre portarias; e de uso de republicação tardia para o fim de retificação normativa. Tais problemas foram endereçados pelas seis portarias de consolidação GM/MS publicadas em 3 de outubro de 2017, via autorização contida no art. 13, $\S 2^{\circ}$ da LC $n^{\circ}$ 95/98, segundo a qual é possível implementar alterações de diversas ordens nos projetos de lei de consolidação. As possibilidades vão desde a introdução - e implicitamente supressão - de agrupadores, passando pela renumeração e reposicionamento de artigos consolidados, assim como a fusão de disposições repetitivas, a atualização da denominação de órgãos e entidades da administração pública, a atualização de termos antiquados e modos de escrita ultrapassados, a atualização do valor de penas pecuniárias, a eliminação de ambiguidades decorrentes do mau uso do vernáculo, a homogeneização terminológica, a supressão de dispositivos declarados inconstitucionais, a indicação de dispositivos não recepcionados pela Constituição Federal, e a declaração expressa de revogação de dispositivos implicitamente revogados. Tais alterações evidenciam uma terceira grande finalidade da consolidação de correção e atualização da técnica legislativa.

Em especial, a possibilidade de homogeneização terminológica impõe um desafio insolúvel no processo consolidador, haja vista existirem termos técnicos muitas vezes ambíguos e utilizados com diferentes conotações por órgãos estatais distintos. Assim, o processo consolidador não deve pretender ser autônomo, mas apoiado por medidas paralelas de construção do consenso em torno a conceitos fundamentais da área consolidada. Não por acaso, os passos finais para publicação das últimas portarias de consolidação que conformam a primeira constelação consolidadora ministerial - a Consolidação do SUS -, mediante publicação das portarias de consolidação das secretarias do Ministério da Saúde, foram acompanhadas da confecção de um glossário de termos normativos presentes na Consolidação do SUS (21). Sem ele e a progressiva uniformização terminológica da área, o esforço consolidador poderia atropelar discussões setoriais de ordem técnica e conceitual. Em outras palavras, a função da consolidação também se afirma pela negação de pretensão totalizante, mantendo abertos canais de decisão das áreas responsáveis pela formulação do conteúdo normativo.

\section{A especificidade da consolidação: um ser único}

A Constituição Federal de 1988 elenca os instrumentos a que se destina o processo legislativo no art. 59, que prevê, em seu parágrafo único, a regulamentação, por lei complementar, da elaboração, redação, alteração e consolidação das leis. 
Com isso, a Constituição Federal de 1988 identificou a consolidação como um dos quatro pilares da vida institucional das leis. Como toda manifestação cristalizada de direito público, os diplomas normativos, em suas diversas apresentações - Constituição, leis, decretos, portarias, resoluções -, são instituições cuja existência se deve ao ordenamento jurídico e a uma teoria do direito público. Os instrumentos normativos detêm início, meio e fim, com especial interesse na vivência da norma. O parágrafo único do art. 59 descreve precisamente esse itinerário da vida institucional das leis em sentido formal produzidas por processo legislativo e o faz enunciando os quatro momentos relevantes dessa vivência que se resumem ao início - elaboração e redação -, ao fim de uma versão do comando normativo - alteração - e ao meio de vigência das leis por intermédio de sua organização e transparência - consolidação. A consolidação, portanto, é o construto de direito público adequado, por expressa dicção constitucional, à manifestação das leis em sua vivência, ou seja, à presença institucional das leis no ordenamento jurídico.

Por escolha constitucional expressa, a consolidação deve ser o meio normal de preservação, manifestação e percepção da norma pela sociedade. Quando a prática institucional brasileira se abstém de implementar a consolidação das leis e, por decorrência, dos demais diplomas normativos infralegais, ela corrói a carga normativa nacional ao extirpar do processo de criação, vivência e extinção dos instrumentos normativos um dos aspectos essenciais enunciados expressamente pela Constituição. A primeira conclusão derivada do art. 59, parágrafo único, da Constituição Federal de 1988 é a de que a consolidação é um dos momentos necessários do processo legislativo e, por decorrência, do processo de produção de normas em geral. Uma segunda conclusão igualmente relevante é a de que a consolidação não se apresenta como uma espécie normativa ordinária, pois sua função não é a de inovar no ordenamento jurídico, mas de, precisamente, organizar as espécies normativas que promoveram a inovação.

A consolidação é uma manifestação do processo normativo e, como tal, detém identidade jurídica própria, destacada do conjunto de normas que consolida. A interpretação extensiva reinante na Imprensa Nacional de somente publicarem normas numeradas tem prosperado, atualmente, sob a falsa percepção de que uma consolidação seria mais um diploma normativo sujeito às regras de identificação sequencial dos instrumentos normativos, esquecendo-se que a única função da consolidação é a de organizá-los; ela tem, portanto, uma função de metanorma, ou seja, de uma linguagem organizacional das normas que absorve. 
O entendimento de que consolidações devem obrigatoriamente ser numeradas, em clara transposição para as consolidações das regras aplicáveis aos diplomas normativos ordinários, revela uma confusão entre os vários instrumentos normativos e a consolidação, que não é um dentre vários diplomas normativos, mas uma fase do processo normativo manifestada continuamente durante a vivência da norma consolidada de função claramente distinta daquelas informadoras das normas que consolida.

Por isso, em homenagem à natureza processual da consolidação, ela não deve ser numerada até mesmo para que possa ser evidenciado o seu ethos de organização contínua e unificada de diplomas normativos conexos. Deve existir apenas uma consolidação de diplomas normativos conexos ou afins por área de pertinência temática. Sua pretensão de fase processual de vivência da norma para a apresentação atualizada e organizada da informação jurídica é incompatível com a existência de consolidações sequenciais numeradas, senão quando a própria estrutura consolidadora promova a divisão de uma grande temática em várias consolidações. Nesse caso, a numeração sequencial não se propõe a identificar as diversas versões da consolidação, mas os subtemas tratados por cada consolidação de uma área, como ocorreu com a Consolidação GM/MS do SUS, subdividida em seis portarias de consolidação. A identificação numérica das portarias de consolidação do Gabinete do Ministro da Saúde serve única e exclusivamente ao efeito relacional entre as portarias de consolidação; não se presta, como ocorre com as normas em geral, à identificação da norma no tempo, indiferentemente ao seu conteúdo. Em outras palavras, a opção pela identificação numérica das portarias de consolidação do Gabinete do Ministro da Saúde foi meramente uma opção. Ao invés de numerar cada uma das seis portarias de consolidação, poder-se-ia inserir a temática predominante, o que, aliás ocorre no jargão de tratamento dessas portarias. A portaria de políticas do SUS é uma forma autoevidente de referência à Portaria de Consolidação GM/MS $n^{\circ} 2$; a portaria de redes do SUS representa a Portaria de Consolidação GM/MS $n^{\circ} 3$; a portaria de sistemas e subsistemas do SUS é outra forma de se referenciar à Portaria de Consolidação GM/MS $\mathrm{n}^{\circ}$ 4; e assim por diante. Se a opção tivesse sido por reunir todas essas temáticas em uma única portaria de consolidação, não faria o menor sentido denominá-la de portaria $\mathrm{n}^{\circ} 1$, quando se sabe que não existirá, em condições normais e desejáveis, a de número 2, 3, 4 etc. De forma similar, esse mesmo raciocínio se aplica a alguns outros tipos de normas com ocorrência singular, que se apresentam como tipos-ideais para a interpretação do regime jurídico aplicável à consolidação, tais como as constituições, as leis orgânicas e os regimentos internos. 
O primeiro decreto regulamentador da LC n 95/98 previa a constituição de comissões de consolidação e revisão de atos normativos, no âmbito da consultoria jurídica de cada ministério (art. 41 do Decreto $n^{\circ} 2.954$, de 29 de janeiro de 1999), ligeiramente alterado pelo Decreto $n^{\circ} 4.176 / 2002$, para comissões permanentes de consolidação e revisão de atos normativos, coordenadas, nos ministérios, por bacharel em direito em exercício na correspondente consultoria jurídica e ao menos um membro integrante da carreira jurídica da Advocacia-Geral da União. Embora o Decreto n 9.191/2017, em vigor a partir de $1^{\circ}$ de fevereiro de 2018, tenha revogado o Decreto $n^{0} 4.176 / 2002$, e sido silente em relação às comissões de consolidação, a previsão regulamentar inicial de comissões permanentes de consolidação é mais uma evidência de que a consolidação corporifica um processo contínuo de organização de conteúdo normativo infenso à numeração. Trata-se de medida identificadora despicienda, contraproducente e induzidora da impressão de que seriam desejáveis consolidações sequenciais numeradas, quando, na maior parte dos casos, determinada área de atuação governamental somente terá uma consolidação. Mesmo na hipótese de existiram modificações substanciais no conteúdo de uma consolidação, ela deve permanecer com o mesmo identificador por não inovar, ela mesma, no ordenamento jurídico. São as diversas versões da consolidação, no tempo, que importarão às discussões de direito intertemporal. Tais versões não dependem, entretanto, de numeração sequencial de consolidações, mas de esforço de transparência quanto ao versionamento e rastreabilidade normativa das consolidações, que é dever do Estado manter para toda a sociedade. Não se está aqui advogando pela impossibilidade jurídica da numeração de consolidações, mas a exigência presente de que consolidações sejam necessariamente numeradas é que está sob escrutínio, no banco dos réus, por se assentar no argumento frágil de que, quando os decretos regulamentadores da LC n 95/98 exigiram numeração sequencial das leis e atos normativos infralegais, o teriam igualmente exigido para as consolidações.

A LC n 95/98 e os decretos regulamentadores que, entre outras providências, exigem numeração sequencial de atos normativos claramente o fazem para ordenação das espécies normativas ordinárias, não se aplicando à consolidação, como fase processual da vivência das normas. O objeto de disciplina da LC n 95/98 e de seus decretos regulamentadores é o conjunto das normas e os processos de elaboração, redação, alteração e consolidação. Embora as regras de estruturação das normas e de sua articulação, redação e alteração informem a consolidação, elas não são automaticamente replicáveis nela.

É o caso, por exemplo, do previsto no art. $4^{\circ}$ do Decreto $n^{\circ} 10.139 / 2019$, conhecido como Decreto do Revisaço, que dispõe que os atos normativos estabelecerão data certa 
para a sua entrada em vigor e para a sua produção de efeitos de, no mínimo, uma semana após a data de sua publicação e sempre no primeiro dia do mês ou em seu primeiro dia útil. Trata-se de dispositivo que não se aplica às consolidações, tendo em vista a finalidade da ordem normativa voltada a prevenir surpresas ao administrado advindas de inovação normativa. Como a consolidação não se presta à inovação normativa, é evidente não estar submetida à regra de postergação de vigência. Pelo contrário, é da natureza da consolidação que entre em vigor na data de sua publicação para precisamente garantir a estabilidade normativa e facultar a atualização contínua do conteúdo normativo dos diplomas consolidados.

A não aplicação da regra de vacatio legis do Decreto $n^{\circ} 10.139 / 2019$ às consolidações é indicativa de que podem existir outras regras igualmente inaplicáveis. Quando o Decreto $n^{\circ} 10.139 / 2019$ identificou o seu objeto - a revisão e consolidação dos atos normativos inferiores a decreto, editados por órgãos e entidades da administração pública federal direta, autárquica e fundacional -, deixou transparente que, de um lado, está o processo de revisão e consolidação das normas e, de outro, estão as portarias, as resoluções, as instruções normativas, os ofícios e avisos, as orientações normativas, as diretrizes, as recomendações, os despachos de aprovação e qualquer outro ato inferior a decreto com conteúdo normativo destinados a serem revisados e consolidados. Os arts. $2^{\circ}$ a $4^{\circ}$ do Decreto $n^{\circ} 10.139 / 2019$ se destinam a editar regras de manifestação dos atos normativos inferiores a decreto destinados a serem consolidados, tanto no que diz respeito às formas normativas autorizadas - portarias, resoluções ou instruções normativas -, quanto no que diz respeito à estrutura, articulação, redação, formatação, publicação, vigência e produção de efeitos. Já os arts. $5^{\circ}$ e seguintes do Decreto $n^{\circ} 10.139 / 2019$ se destinam a disciplinar o processo propriamente dito de revisão e consolidação dos atos normativos identificados nos artigos anteriores. Dessa constatação exsurge a conclusão de que, quando o art. $3^{\circ}$ do Decreto $n^{\circ}$ 10.139/2019 foi alterado pelo Decreto $n^{\circ} 10.437 / 2020$, que também acrescentou os arts. $3^{\circ}$ A e $3^{\circ}-B$ ao Decreto $n^{\circ} 10.139 / 2019$, a matéria ali veiculada não dizia respeito às consolidações, mas às normas objeto de consolidação. Em especial, à previsão do art. $3^{\circ}$ B, III, do Decreto $n^{\circ} 10.139 / 2019$, de numeração sequencial dos atos normativos inferiores a decreto, que se localiza-se entre os dispositivos voltados à disciplina dos atos normativos destinados a serem consolidados; não à consolidação mesma.

Assim, a determinação de numeração sequencial tanto em nível de emendas à Constituição, leis complementares, leis ordinárias, leis delegadas (art. $2^{\circ}, \S 2^{\circ}$ da LC $n^{\circ}$ 95/98), medidas provisórias e decretos (arts. $3^{\circ}$ e $4^{\circ}$ do Decreto $n^{\circ} 9.191 / 2017$ ), quanto em 
nível de atos normativos inferiores a decreto (art. $3^{\circ}-B$, III do Decreto $n^{0} 10.139 / 2019$, incluído pelo Decreto $n^{\circ} 10.437 / 2020$ ) detém a nobre função de ordenar os diplomas normativos federais de diversos níveis no ordenamento jurídico brasileiro para, dentre outros fins, viabilizar sua revisão e consolidação.

A numeração sequencial não se apresenta como dispositivo vinculante das consolidações. A numeração sequencial destina-se à identificação de normas ordinárias; não à identificação das consolidações que, por incorporarem finalidade distinta da das normas ordinárias, são excepcionais e com pretensão de preservação, no tempo, da contínua organização das normas ordinárias. A obrigatoriedade geral de numeração sequencial das consolidações enclausura o processo consolidador na lógica, que informa a identificação das normas que ele mesmo pretende organizar, e grava com transitoriedade um processo ordenado para ser permanente.

Hoje, na Administração Pública Federal, é a própria Imprensa Nacional que inviabiliza consolidações não numeradas por imposição de formulário eletrônico de encaminhamento de matérias para publicação no Diário Oficial da União, muito embora não exista, no Decreto $n^{\circ}$ 9.215, de 29 de novembro de 2017, que dispõe sobre a publicação no Diário Oficial da União, nem mesmo na Portaria IN/SG/PR n 9, de 4 de fevereiro de 2021, que dispõe sobre publicação de atos no Diário Oficial da União, a exigência de numeração compulsória de diplomas normativos em geral, nem muito menos de consolidações, em especial.

Finalmente, um último aspecto de especificidade da consolidação está na espécie normativa consolidadora. Quando o art. $13, \S 2^{\circ}$ da LC $n^{\circ}$ 95/98 prevê a possibilidade de alterações nos projetos de lei de consolidação, ele inaugura uma nova espécie normativa replicável em outros níveis hierárquicos ou de competência normativa. Da mesma forma que a LC n 95/98 prevê a existência de projetos de lei de consolidação, bem como a extensão do esforço consolidador aos decretos de conteúdo normativo e geral e demais atos normativos inferiores em vigor (art. 16, caput, da LC n 95/98), ela, e por decorrência, reconhece implicitamente a existência da lei de consolidação, do decreto de consolidação, da portaria de consolidação, da resolução de consolidação e de quaisquer outras espécies normativas consolidáveis. Não por acaso, um dia após a aprovação das Portarias de Consolidação GM/MS do SUS, foi aprovada a Portaria GM/MS n².500, de 28 de setembro de 2017, que diferencia as portarias de efeitos concretos, das portarias normativas e estas das portarias de consolidação. 


\section{Conclusão}

Não se pode negar que o principal momento da consolidação é a sua elaboração inaugural, que se aventura a coletar, tratar, compilar, revisar, estruturar e publicar a consolidação temática de determinada área de atuação estatal. Ela, entretanto, somente adquire sua vivência institucional integral quando vista como um processo de contínua e permanente atualização.

A consolidação é uma instituição de direito público que se distingue dos instrumentos normativos que consolida, caracterizando-se não somente pela apresentação na forma de uma integração dos diplomas normativos pertinentes a determinada matéria, revogando-os formalmente, sem modificação do alcance nem interrupção da força normativa dos dispositivos consolidados, mas também por sua função e especificidade.

Assim, a consolidação é teleologicamente - e finalidade é o que delimita os atributos jurídicos de uma instituição de direito público - o meio de preservação, manifestação e percepção da norma pela sociedade, uma garantia institucional de segurança jurídica, um espaço de reestruturação orgânica neoinstitucional de dispositivos normativos conexos ou afins, uma pauta para elaboração de novas normas e uma oportunidade contínua e permanente de correção e atualização de técnica legislativa.

Para o cumprimento de sua finalidade de direito público, a consolidação se apresenta com identidade própria destacada dos diplomas normativos que consolida, como produto de um processo consolidador integrante e identificador das etapas de vivência normativa, ela mesma uma espécie normativa extraordinária, de ocorrência singular, pois não se presta à inovação normativa própria às demais espécies normativas ordinárias e tem a pretensão de se eternizar no ordenamento jurídico.

\section{Referências}

1. Rizek Júnior R. O processo de consolidação e organização legislativa. São Paulo: Universidade de São Paulo (Tese de Doutorado), 2009.

2. Amaral GLD et al. Quantidade de Normas Editadas no Brasil: 30 anos da Constituição Federal de 1988. Curitiba: Instituto Brasileiro de Planejamento e Tributação; 2018.

3. Lima JAO. Consolidação de Normas Jurídicas: encontro entre Direito, Ciência da Informação, Filosofia da Linguagem e Lógica, a convite do neoinstitucionalismo. Brasília: Tese de Doutorado defendida no Programa de Pós-Graduação em Direito, Estado e Constituição da Universidade de Brasília (Orientador: Prof. Marcio lorio Aranha), 2019.

4. Orminston GL, Schrift AD (eds.). The Hermeneutic Tradition: From Ast to Ricoeur. Albany: State University of New York; 1990. 
5. Hirsch ED. Validity and Interpretation. New Haven: Yale University Press; 1967.

6. Poscher R. Hermeneutics and Law. In: Foster MN, Gjesdal K. The Cambridge Companion to Hermeneutics. Cambridge: Cambridge University Press; 2019. p. 326-353.

7. Oliveira MDRM et al. Judicialização da saúde: para onde caminham as produções científicas? Saúde em Debate. Apr-Jun 2015; 39:105.

8. Aranha MI. Interpretação Constitucional e as Garantias Institucionais dos Direitos Fundamentais. 2. ed. São Paulo: Atlas; 2000.

9. Aranha MI. Segurança jurídica stricto sensu e legalidade dos atos administrativos: convalidação do ato nulo pela imputação do valor de segurança jurídica em concreto à junção da boa-fé e do lapso temporal. Revista de Informação Legislativa. 1997; 134:59-73.

10. Schmitt C. Freiheitsrechte und institutionelle Garantie der Reichsverfassung. In: Verfassungsrechtliche Aufsätze aus den Jahren 1924-1954: Materialen zu einer Verfassungslehre. Berlin: Duncker \& Humblot; 1958. p. 140-173.

11. Savigny FKV. De la vocación de nuestro siglo para la legislación y la ciencia del derecho. Tradução de Adolfo Posada. Buenos Aires: Editorial Atalaya; 1946.

12. Wüster E. Die Allgemeine Terminologielehre: ein Grenzgebiet zwischen Sprachwissenschaft, Logik, Ontologie, Informatik und den Sachwissenschaften. Berlin: Walter de Gruyter; 2009.

13. Diemer A. Studien zur allgemeinen Ordungslehre. International Classification. 1974; 1(2): 61-68.

14. Dahlberg I. Zur Theorie des Begriffs. International Classification. 1974; 1(2):12-19.

15. Dahlberg I, Dahlberg W. Prinzipien der Klassifikation. Frankfurt: Gesellschaft für Klassifikation (Simpósio em Munique, Studien zur Klassifikation 1); 1977.

16. Weihs C, Gaul W (eds.). Classification: The Ubiquitous Challenge. Berlin/Heidelberg: Springer; 2005.

17. Lima JAO. Modelo Genérico de Relacionamentos na Organização da Informação Legislativa e Jurídica. Brasília: Tese de Doutorado em Ciência da Informação, sob orientação do prof. Murilo Bastos da Cunha, na Universidade de Brasília, 2008.

18. Maccormick N, Weinberger O. Law as Institutional Fact. In: Maccormick N, Weinberger O. An Institutional Theory of Law: New Approaches to Legal Positivism. Dordrecht: Springer Science \& Business Media; 1986. p. 49-77.

19. Lima JAO et al. Casting the Light of the Theory of Opposition onto Hohfeld's Fundamental Legal Concepts. Legal Theory. Cambridge, 2021; 27:1-34,. 
20. Delduque $\mathrm{MC}$, Passos E. Identificação de problemas de redação legislativa encontrados nas portarias normativas do Gabinete do Ministro da Saúde (GM/MS). Cadernos de Informação Jurídica. 2018 jan./jun; 5(1): p. 22-57.

21. Fiocruz. Glossário Lourdes Almeida da Consolidação de Normas do Sistema Único de Saúde. Brasília: Programa de Direito Sanitário da Fiocruz; 2021.

\section{Normas citadas}

Brasil. Constituição da República Federativa do Brasil, de 5 de outubro de 1998. Diário Oficial [da] República Federativa do Brasil, Poder Executivo, Brasília, p. 1, 05 out. 1988.

Brasil. Decreto $n^{\circ} 4.176$, de 28 de março de 2002. Estabelece normas e diretrizes para a elaboração, a redação, a alteração, a consolidação e o encaminhamento ao Presidente da República de projetos de atos normativos de competência dos órgãos do Poder Executivo Federal, e dá outras providências. Diário Oficial [da] República Federativa do Brasil, Poder Executivo, Brasília, p. 1, 1 abr. 2002.

Brasil. Decreto $n^{\circ}$ 9.191, de 1 de novembro de 2017. Estabelece as normas e as diretrizes para elaboração, redação, alteração, consolidação e encaminhamento de propostas de atos normativos ao Presidente da República pelos Ministros de Estado. Diário Oficial [da] República Federativa do Brasil, Poder Executivo, Brasília, p. 16, 3 nov. 2017.

Brasil. Decreto no 10.139, de 28 de novembro de 2019. Dispõe sobre a revisão e a consolidação dos atos normativos inferiores a decreto. Diário Oficial [da] República Federativa do Brasil, Poder Executivo, Brasília, p. 32, 29 nov. 2019.

Brasil. Decreto $n^{\circ} 10.437$, de 22 de junho de 2020. Altera o Decreto $n^{\circ} 10.139$, de 28 de novembro de 2019, que dispõe sobre a revisão e a consolidação dos atos normativos inferiores a decreto, e o Decreto $n^{\circ} 9.215$, de 29 de novembro de 2017, que dispõe sobre a publicação do Diário Oficial da União. Diário Oficial [da] República Federativa do Brasil, Poder Executivo, Brasília, p. 1, 23 jul. 2020.

Brasil. Lei Complementar n 95, de 26 de fevereiro de 1998. Dispõe sobre a elaboração, a redação, a alteração e a consolidação das leis, conforme determina o parágrafo único do art. 59 da Constituição Federal, e estabelece normas para a consolidação dos atos normativos que menciona. Diário Oficial [da] República Federativa do Brasil, Poder Executivo, Brasília, p. 1, 27 fev. 1998

Brasil. Lei Complementar $n^{\circ}$ 107, de 26 de abril de 2001. Altera a Lei Complementar $n^{\circ}$ 95, de 26 de fevereiro de 1998. Diário Oficial [da] República Federativa do Brasil, Poder Executivo, Brasília, p. 1, 27 abr. 2001.

Brasil. Ministério da Saúde. Gabinete do Ministro. Portaria n ${ }^{0} 1.035$, de 4 de junho de 2002. Cria a Comissão Permanente de Consolidação e Revisão de Atos Normativos do Ministério da Saúde. Diário Oficial [da] República Federativa do Brasil, Poder Executivo, Brasília, p. 42, 6 jun. 2002.

Brasil. Ministério da Saúde. Gabinete do Ministro. Portaria n 1.208, de 22 de maio de 2007. Cria a Comissão Permanente de Consolidação e Revisão de Atos Normativos do 
Ministério da Saúde. Diário Oficial [da] República Federativa do Brasil, Poder Executivo, Brasília, p. 65, 23 mai. 2007.

Brasil. Ministério da Saúde. Gabinete do Ministro. Portaria n 815, de 29 de abril de 2008. Aprova o Regimento Interno da Comissão Permanente de Consolidação e Revisão de Atos Normativos do Ministério da Saúde - CPCRAN/MS. Diário Oficial [da] República Federativa do Brasil, Poder Executivo, Brasília, p. 69, 30 abr. 2008.

Brasil. Ministério da Saúde. Gabinete do Ministro. Portaria $n^{\circ} 2.048$, de 3 de setembro de 2009. Aprova o Regulamento do Sistema Único de Saúde (SUS). Diário Oficial [da] República Federativa do Brasil, Poder Executivo, Brasília, p. 61, 4 set. 2009.

Brasil. Ministério da Saúde. Gabinete do Ministro. Portaria $n^{\circ} 2.230$, de 23 de setembro de 2009. Dispõe sobre a aplicação da Portaria $n^{\circ} 2.048 / G M$, de 3 de setembro de 2009, que aprovou o Regulamento do Sistema Único de Saúde (SUS) e dá outras providências. Diário Oficial [da] República Federativa do Brasil, Poder Executivo, Brasília, p. 62, 24 set. 2009.

Brasil. Ministério da Saúde. Gabinete do Ministro. Portaria $n^{\circ} 2.792$, de 15 de setembro de 2010. Dá nova redação ao art. $2^{\circ}$ da portaria $n^{\circ} 2.048$, de 3 de setembro de 2009 , que aprova o Regulamento do Sistema Único de Saúde (SUS), e dispõe sobre sua consulta pública. Diário Oficial [da] República Federativa do Brasil, Poder Executivo, Brasília, p. 61, 17 set. 2010.

Brasil. Ministério da Saúde. Gabinete do Ministro. Portaria $n^{\circ} 319$, de 28 de fevereiro de 2011. Prorroga o prazo de entrada em vigor da Portaria $n^{\circ} 2.048 / \mathrm{GM} / \mathrm{MS}$, de 3 de setembro de 2009. Diário Oficial [da] República Federativa do Brasil, Poder Executivo, Brasília, p. 48, 01 mar. 2010.

Brasil. Ministério da Saúde. Gabinete do Ministro. Portaria n 373, de 5 de março de 2012. Prorroga o prazo de entrada em vigor da Portaria $n^{\circ} 2.048 / \mathrm{GM} / \mathrm{MS}$, de 3 de setembro de 2009. Diário Oficial [da] República Federativa do Brasil, Poder Executivo, Brasília, p. 94, 06 mar. 2012.

Brasil. Ministério da Saúde. Gabinete do Ministro. Portaria $n^{\circ} 2.500$, de 28 de setembro de 2017. Dispõe sobre a elaboração, a proposição, a tramitação e a consolidação de atos normativos no âmbito do Ministério da Saúde. Diário Oficial [da] República Federativa do Brasil, Poder Executivo, Brasília, p. 46, 3 out. 2017.

Brasil. Ministério da Saúde. Gabinete do Ministro. Portaria de Consolidação n 1 , de 28 de setembro de 2017. Consolidação das normas sobre os direitos e deveres dos usuários da saúde, a organização e o funcionamento do Sistema Único de Saúde. Diário Oficial [da] República Federativa do Brasil, Poder Executivo, Brasília, p. 1, 3 out. 2017.

Brasil. Ministério da Saúde. Gabinete do Ministro. Portaria de Consolidação n ${ }^{\circ} 2$, de 28 de setembro de 2017. Consolidação das normas sobre as políticas nacionais de saúde do Sistema Único de Saúde. Diário Oficial [da] República Federativa do Brasil, Poder Executivo, Brasília, p. 61, 3 out. 2017. Suplemento. 
Brasil. Ministério da Saúde. Gabinete do Ministro. Portaria de Consolidação n ${ }^{\circ} 3$, de 28 de setembro de 2017. Consolidação das normas sobre as redes do Sistema Único de Saúde. Diário Oficial [da] República Federativa do Brasil, Poder Executivo, Brasília, p. 192, 3 out. 2017. Suplemento.

Brasil. Ministério da Saúde. Gabinete do Ministro. Portaria de Consolidação nº 4, de 28 de setembro de 2017. Consolidação das normas sobre os sistemas e subsistemas do Sistema Único de Saúde. Diário Oficial [da] República Federativa do Brasil, Poder Executivo, Brasília, p. 288, 3 out. 2017. Suplemento.

Brasil. Ministério da Saúde. Gabinete do Ministro. Portaria de Consolidação n ${ }^{\circ} 5$, de 28 de setembro de 2017. Consolidação sobre as ações e os serviços de saúde do Sistema Único de Saúde. Diário Oficial [da] República Federativa do Brasil, Poder Executivo, Brasília, p. 360, 3 out. 2017. Suplemento.

Brasil. Ministério da Saúde. Gabinete do Ministro. Portaria de Consolidação nº 6, de 28 de setembro de 2017. Consolidação sobre o financiamento e a transferência dos recursos federais para as ações e os serviços de saúde do Sistema Único de Saúde. Diário Oficial [da] República Federativa do Brasil, Poder Executivo, Brasília, p. 569, 3 out. 2017.

Suplemento.

\section{Colaboradores}

Aranha MI contribuiu com a concepção e redação do artigo. Lima JAO contribuiu com a redação e revisão crítica do artigo.

\section{Como citar este artigo}

Aranha MI, Lima JAO. Consolidação de atos normativos: a especificidade da técnica legislativa e a consolidação do Sistema Único de Saúde. Cadernos Ibero-Americanos de Direito Sanitário. 2021 dez.;10(Suplemento):32-52. 